\title{
Promoting an Interdisciplinary Approach in Scientific Research and Training Human Resources for Vietnam's Libraries and Archives
}

\author{
Loan Thuy Bui \\ Faculty of Social Sciences and Humanities, University of Social Sciences and Humanities of Ho Chi Minh City, Vietnam
}

Copyright $\mathrm{C} 2016$ by authors, all rights reserved. Authors agree that this article remains permanently open access under the terms of the Creative Commons Attribution License 4.0 International License

\begin{abstract}
Libraries and archives offices in Vietnam are going marching forward, hand in hand, on the way to international integration. There are many theoretical and practical issues both library and information science and archival science have in common. In the past decades scientific research activities in the field of library, information and archives were conducted independently employing a monophyletic thinking style. Therefore, promoting renovation of scientific research thinking, as well as scientific topics towards inter- and multi-disciplinary approach in library and information science and archival science, has become urgent in the country. This paper aims to answer the questions: Why change? Why change at this point in time? What are the study fields? What kinds of study subjects or phenomena must be approached in an interdisciplinary manner? And how can we bring about the changes?
\end{abstract}

Keywords Scientific Research Activities, Interdisciplinary, Library and Information Science, Archival Science, Vietnam

\section{Introduction}

Currently Vietnamese researchers of library and information science and archival science are finding solutions to the aforementioned issues rising in the process of international integration by library administration management and archives administration management. Carrying out their work during so many years, they resorted to a monophyletic approach; hence the approach methods of the two sciences were isolated, not coordinated and cooperated.

For this reason, instead of a joint treatment towards in the practical activities of libraries and archives offices, particularly; document preservation and technology of document digitization, organization of system of reference numbers/coding system, records management programmes, audiovisual documents management and, web technology, etc the same issues were studied separately, despite the fact that the two sciences maintain a strong interdisciplinary interrelationship.

In fact the curriculum of training human resources at library and information faculties, contains but one subject related to archives, that is general archival science. Similarly, that of archival science and office administration management of the Universities of Social Sciences and Humanities, of both Hanoi and Ho Chi Minh City, contains but a subject related to library, i.e. general library science. Scientific research activities undertaken by the disciplines of library and information science and archival science, have been largely are characterized by isolationism and closed doors.

\section{Why Renovate from a Monophyletic Approach to an Interdisciplinary Approach}

To renovate their work, Vietnamese researchers of library and information science and archival science will benefit from a have to switch to inter- and multi-disciplinary approach for the following reasons.

Academically: modern scientific research develops in an interdisciplinary manner all by itself. The nature of modern thinking is what connected and interwoven named complex, thinking (1). Library and information science and archival science maintain are close ties to each other, having reached a highly specialized level, needing mutual expansion, connection and penetration.

Besides this, library administration management and archives administration management always develop in a 
manner inextricabe linkage with political institutions, economic conditions, history, culture, science and the technological development of a given country. In addition many research questions imply themselves interdisciplinarity. This approach enables researchers to observe from different angles and exactly to depict the multifaceted parameters affecting the changes of libraries and archival offices.

The technical processing of archival materials, preservation and organization of utilization of information resources, archival materials of national property and archival materials of especially rare value... are related not only to information technology, but also the knowledge of many other branches of science.

Librarianship and archives administration are professions aiming to apply theory and technology of creating, selecting, organizing, preserving, disseminating and utilizing collections of information in all formats and meeting the needs of a specific user. The content of training programmes for the human resources of libraries, information and archives in the world are oriented towards providing access to vast amounts of accumulated knowledge and information.

In recent years many countries continue to increasing the quantity and bettering the contents of education for human resources of libraries and archives. The programmes may offer a variety of courses including; basic archival theory, aspects of library and information science, document management, records management, research methods, methods and/or practice of appraisal, arrangement, description, preservation, reference services, outreach, legal concerns and ethics.

For the time being the human resources of Vietnam's libraries are trained at informatics faculties or library and information faculties, those of archives - at archives and office administration management faculties of the Universities of Social Sciences and Humanities and the Universities of Culture of both Hanoi and Ho Chi Minh City.

The interdisciplinary approach in designing the education programme for human resources of libraries and archives makes it feasible to link the theories and methods of both professions to achieve higher productivity at work and, enhanced cooperation with colleagues in performing daily operations, particularly in handling digital information sources.

The information age raises a number of practical issues of libraries and archives offices, needing cooperation in search of solutions tending towards this approach, especially those studying the properties and behaviour of information, the forces governing the flow of information, and the means of processing information for optimum accessibility and usability. The issues in question are related to the body of knowledge of the originals, collection, organization, storage, retrieval, interpretation, transformation and utilization of information.

\section{Research Methodology}

This study was done with results from the fieldwork that the author conducted and presented in her book published in 1997 named The Current State and Future Development of Library Science in Vietnam, and from secondary data in the articles about library science and archive science published in the Journal of Library, the Journal of Information and Documentation Magazine, and the Journal of State Records Management and Archives, and from the reports in the Proceedings of Science Conference, held in Vietnam, about library science and archive science. Besides this, Vietnam's strategies for developing the department of Library Information and Science and that of State Records Management and Archives to 2020, and vision 2030, were also studied.

Based on the strategies for developing the department of Library Information and Science and that of State Records Management and Archives, this study was conducted to analyze the need to link the potential strength of scientific research with a view to reach interdisciplinary approach. The aim of the study is to help solve scientific problems in reality, in ways that both meet the social needs of Vietnam and agree with the policies of the Party and the Government of Vietnam on practicing library information and archive.

Accordingly, it can be concluded that the interdisciplinary approach in scientific research is an essential and efficient tool, which greatly benefits the of Vietnam's science. Such an approach promotes and makes changes to scientific researches; it also trains human resources for libraries, information centers and storage agencies, as well as for the department of Library Information and Science and that of State Records Management and Archives.

\section{Data Collection}

During the data collection process, the author used the method of bibliometries, which includes statistics from scientific papers and studies in the country and from all doctoral thesis defended (from 1961 to 2000) in foreign countries. Such statistics had been entirely systematized before the content was analyzed and evaluated, and there were also considerations regarding which problems have and have not been studied. Accordingly, trends for conducting major scientific researches in the fields of the library and archive information were discovered. Then, the author compared such trends with the requirements of practical development, studied the practical policies in Vietnam, and proceeded to analyze and evaluate of the content of the research. The author also found that there are two main trends for researching. as follows:

\subsection{The Topics of Research by Library and Information Science in Vietnam}

The topics of research by library and information science 
since 2000 up to now, focused on the research on (1):

- Electronic and digital libraries such as; library automation, automation of library services, integrated library system, copyrights and licensing, metadata creation, digital archives, digital preservation, theory and practice of digital libraries, digital library management systems ...;

- Information products and services in the context of forming the information market in the country, for example, electronic reference services, library services in the digital age, marketing of information products and services for libraries, digital collection development, supporting services for special lectures, seminars, conferences, events; open learning environment, community services ...;

- Legal aspects of access to information, development of quality information sources, e.g. impact of the renovation of government management on library administration management, government policies affecting the information market, rights to information and information safety ...;

- Developing reference tools in search of information sources;

- Preservation of electronic documents and efficient utilization of these and communications, and information resources sharing;

- Issues of education and training of human resources for libraries in the electronic era and digital age;

- Economics of information and library, organizational structure of information systems;

- Social function of libraries in the knowledge economy, information society, learning society such as library access as part of better quality of life, library for development of culture and aesthetic enjoyment, library for healthy development of human constitution and intellect in Internet environment ...

\subsection{The topics of Research by Archival Science in Vietnam}

From 1962 to 2012, Vietnamese researchers of Archive Science followed two main research directions (2):

- Study to assist State management in practicing managing and archiving State records, in order to provide the scientific foundation for solving the problems related to organizing the sector of Archive Science and managing the State in the practice of Archive Science. Examples include organizing a network of repositories in Vietnam, determining the authority to manage the archives of the National Archives Centre, standardizing store personnel and output quota, etc.

- Study theoretically and practically the practice of managing and archiving State records. Examples include the terminological system of State Records Management and Archives in Vietnam, which determines the value of the documents, identifies the resources and the document components of State management and many other materials liable to be put in storage of all levels, and the time term for preserving the documents of state management, accounting, and HR (human resources) documents, etc.; study the construction of principles, the methods of building the lookup tool systems, the description of archives at national archives centers, published documents, principles and methods of compilation of guidance using archives, declassified documents, etc... study the solutions to secure documents in the hot and humid tropical climate conditions with thriving insects and fungi, etc.; study to determine the technical terms for building specialized repositories in Vietnam, etc.

- Study the issues of digital information storage. Examples include building requirements and records management solutions, electronic documents, data standards in the creation, using and storing data descriptors with electronic-stored documents.

- Study the problems of application of advanced technologies into the preservation of archives, storage business processes of professional and specified documents.

The research of archival science in accordance with "The master plan of development of record management, archives by 2020 and vision to 2030 " will focus on the following questions (3):

- Perfecting the network of archival offices from central level down to local level;

- Draft and issuance of documents guiding the implementation of the Law on Archives;

- Standardization of work positions in archives administration;

- Solutions for capacity building for archives staff;

- Solutions for renovation of inspection and control activities in archives work;

- Standardization of records management processes and procedures in archives; utilization of automated techniques for management of electronic records regardless of format;

- E-government and the issues facing archives work;

- Building the system of technical and economic norms in archives work;

- Deployment of archival programmes, e.g. programmes of publication and digitization of archival documents, programme of archival documents of national property, programme of digital archives and electronic records;

- Solutions to improve the quality of filing and transferring by archivists to current archives;

- Utilization of historical material sources about Vietnam's seas and islands, military history and historical facts of the country by way of archival materials;

- Conservation and promotion of the values of wood administrative materials of Dynasty Nguyen world documentary heritage; 
- Conservation of archival documents at risk of acidification and faded ink;

- Solutions for organizing modern models in utilization of archival documents;

- Starting the transaction process of collection, acquisition, classification, appraisal, preservation, restoration, organization of utilization of archival documents of national property, administrative management, audiovisual records, science and technology records, electronic documents, inspection documents, medical records, private archival documents, etc...

- Conservation techniques of archival documents of traditional forms;

- Solutions for expansion and renovation of forms of organizing utilization of archival documents;

- Improvement of the system of traditional finding aids in search of traditional and modern archival documents;

- Improvement of the system of archival centers to meet the requirements of safe preservation and efficient use of documents in State archival fonds.

In the research articles published from 2010 to 2015 on three journals specialized in the field of library science and archival science in Vietnam, such as Information Data (4 issues per year), Library of Vietnam (6 issues per year), State Records Management and Archives of Vietnam (12 issues per year), research topics overlapped most at electronic documents and matters related to electronic documents such as digital archives, preservation of electronic documents and, the efficient utilization of electric documents. For example, from 2010 to 2015, the journal of Information and Documentation published 16 articles with topics concerning electronic documents and matters related to electronic documents on a total of 131 research articles on many different topics; Vietnam Library Journal published 12/220 articles; State Records Management and Archives published 19/269 articles.

\begin{tabular}{|c|c|c|c|c|c|c|}
\hline $\begin{array}{c}\text { Name of the } \\
\text { journal }\end{array}$ & 2010 & 2011 & 2012 & 2013 & 2014 & 2015 \\
\hline $\begin{array}{c}\text { Information and } \\
\text { Documentation }\end{array}$ & $2 / 14$ & $3 / 13$ & $2 / 22$ & $4 / 3$ & $2 / 24$ & $3 / 25$ \\
\hline $\begin{array}{c}\text { Library of } \\
\text { Vietnam }\end{array}$ & $3 / 26$ & $1 / 32$ & $3 / 48$ & $1 / 36$ & $2 / 38$ & $2 / 38$ \\
\hline $\begin{array}{c}\text { State Records } \\
\text { Management } \\
\text { and Archives }\end{array}$ & $2 / 28$ & $2 / 45$ & $1 / 47$ & $6 / 70$ & $6 / 44$ & $2 / 35$ \\
\hline
\end{tabular}

For the study of the preservation of paper documents, almost all results of scientific research by archival science on the preservation of archival documents are used by Vietnam's libraries in the preservation of documents. Applied in the country's libraries, these have been standardized by government agencies into norms guiding the preservation of archival documents. For example, the document "Guidance for preservation of archives" of the National Library of Vietnam was issued based on
Document No. 111 of the State Archives Department dated 4th April 1995, regulating matters related to storehouses and equipment of preservation, organization of documents in storehouse, measures and techniques of preservation and restoration of documents.

\section{Results and Discussions}

\subsection{In Vietnam, There Is No Interdisciplinary Research in the Field of Scientific Research on Library and Archival Science}

The methods of interdisciplinary research between the two closely related sciences have only been mentioned in the social sciences and humanities in Vietnam for the past 10 years. However, they have been mentioned mainly in the fields of cultural studies, history, archeology, and ethnography.

In the field of library science and archival science, there have not been any projects on interdisciplinary research yet; the self-contained isolation between the two branches, which are library science and archival science, is popular. Experts on the two sciences therefore only publish studies only under narrow specialization. As a result, the researchers on school library science, information science, and archival science are inexperienced when it comes to organizing interdisciplinary studies. Meanwhile, the practical development of libraries and archival centers in Vietnam is requiring results, which can only be best achieved by applying interdisciplinary research methods.

The overlapping of research is most evident in studies related to electronic documents in libraries and archive centers in Vietnam. This is due to the limited abilities of interdisciplinary cognition as well as of combining of the theories and methods of these two sectors in their researches. Therefore, there should be additional measures to promote scientific researches.

Apart from that, an interdisciplinary approach also helps achieve solutions to area studies of a problem by analyzing those as a system problem in the interdependent relationship between the resources in libraries and archival offices. Practical activities of libraries and archival offices in Vietnam are witnessing and increasingly expanded the application of information technology increasingly expanded. Digital technology has strongly influenced the development of information resources processed, preserved and utilized in national and provincial libraries and archival centers.

\subsection{The Solutions to Implement}

\subsubsection{Scientific Researchers have to change Their "Viewpoint"}

Scientific researchers have to change their "viewpoint", proceeding from the only matrix system to the complex one. 
In the practice of libraries and archival offices, an interdisciplinary approach agrees with the studying of the transformation process from traditional services to modern services, from internal services to outside services.

To analyze the directions of research of both sciences at universities, national archives centers, large libraries like the National Library, the National Department of Scientific and Technological Information, the libraries of universities, research institutes and to switch them to an interdisciplinary approach in order to realize a breakthrough in the scientific research by these two sciences in Vietnam.

Levels of applying an interdisciplinary approach in scientific research on library and archives in Vietnam may be as follows:

Level 1 lowest: to apply some concepts and methods of library and information science to archival science and vice versa.

Level 2: to compare the theoretical systems of the two sciences. For example, the laws of development of library with those of archives in the world (molded into theory), the principles of organizing library with those of archives, the principles of organizing utilization and preservation of materials etc. in other countries with different political institutions in search of common features, similarities and differences with a view to applying theoretically new oriented ideas and practical solutions.

Level 3: to establish the intersections to focus on the cooperation in research as meeting points of interest of both sciences. Hence to identify the topics of concrete studies, organize research teams to bring into play the intellect of scientists trained by various sources, and aggregate the knowledge of the two sciences.

\subsubsection{Similar Directions of Research Should Promote Strong Cooperation between Experts of Library and Information Science and Experts of Archival Science in Accordance with an Interdisciplinary Approach.}

\subsubsection{Preservation of Audiovisual Archival Documents and Electronic Archival Documents}

Nowadays the sources of electronic information are undergoing a strong development, hence the issue of cooperation in the research on solutions for preservation of audiovisual and electronic archives. In addition, it is in the common interest of experts of both sciences that paper documents require concentrated efforts in research on preservation to meet the demands for safety facing the threat of acidification, faded ink in tropical climatic conditions. Their consensus on applying an interdisciplinary approach would create a solid foundation for the interpretation of many intersected disciplines and fields in the research on document management, data management, preservation of archives, information retrieval, information systems, the web, image processing, human-computer interaction, archiving and digital curation, ect ...

\subsubsection{Development of Modern Search Engines for the Efficient Utilization of Archival Documents in Libraries and Archival Centers}

The research on and development of modern search engines for the efficient utilization of archival documents constitutes an urgent need in present-day Vietnam. Thanks to the ever more increasing number of electronic libraries, the card catalogue system as a traditional finding aid has been replaced by the online public access catalogue. The results of scientific research on the construction of a modern finding system of information and the automated methods of finding information in the digital world are widespread now in practical library activities. Meanwhile, the scientific research in the archival field continues towards perfecting the traditional system of finding aids, starting with studies of modern search engines of archival documents. There is a need to take advantage of the results of scientific research on the construction of modern systems and the automated methods of finding information for constructing and developing modern search engines to efficiently use specific archival documents in the current and historically archives of Vietnam.

\subsubsection{Research on Issues of Education and Training of Human Resources}

As in many other parts of the world, library and information science and archival science are terms that have been widely used in this country. They have been used in journal titles, in the names of professional conferences, and commonly for the denominations of librarian schools, archivist schools as well as for the programmes and degrees they offer. For example, the Universities of Social Sciences and Humanities and the Universities of Culture of both Hanoi and Ho Chi Minh City, University of Saigon ... The practice has demonstrated the unquestionable informational overlap between these two knowledge fields beyond the epistemological discussions, since there is a common subject: information or documents with different features and approaches are present in both spaces.

Improving the quality of human resources of libraries, information and archives in the electronic age to meet the new requirements in the management of information and archival resources is a leading concern not only of the administrators of libraries, archives offices but also many researchers in the fields. The future professionals in libraries and archives have a number of similarities in their knowledge, personal qualities and professional skills necessary for successful professional practice and scholarly work. The types of archives and objects using archival documents in libraries and archival offices are getting increasingly diverse, demanding professionalism in the services as well as the capacity of librarians and archivists to collect, analyze, synthesize, process, structure information and effectively utilize the new media resources.

Therefore, the research on solutions to upgrade the capacity of human resources of library, information and 
archives has to be directed towards an interdisciplinary approach with a view to creating opportunities for the professional practioners in search of jobs facing fierce labour competition in a market economy. It is a must to substantiate the necessity to merge the training of specialists in library and information science and specialists of archives at universities of Vietnam into the faculty of information and library similarly in the training model of information universities in some countries or leave the faculty of information and library and the faculty of archives and office administration management independent as they continue to do so until now.

Also needed is the in-depth research on the contents of library and information science programmes of other countries (e.g. USA, Canada, China) to clarify the situation and take action in the concrete conditions of Vietnam.

\subsubsection{The Schools of Training Human Resources}

(Librarians, Archivists, Records Managers) Are Requested to Renovate the Contents of Training Programmes in Accordance with the New Approach

This will be conducted on the basis of designing the subjects of study in information schools of the advanced Western countries to fit the local specific context. To open up trends of training specialists of knowledge, records and information management, information preservation, digital preservation; digital curators, managers of digital collection and preservation project; web archivists ...

The scope of the vocational training programs on library science and archival science will have to be expanded and the approach changed in terms of the designs, moving from a target-based approach to a developmental approach. Under this approach, the educational programs are considered education processes, and education means development. Education is the development in the sense of human development, the potential and experience to be able to master themselves, to cope with challenges in a creatively and proactively manner, making it possible to adapt to an ever-changing and evolving world of professions. This approach focuses on the development of the learner's capacity to understand and to absorb knowledge rather than the transmission of previously determined knowledge content. These transferable skills, which are paid close attention to, include critical thinking, effective communication, group work, problem-solving, mining, and information processing.

The contents of the librarian and archivist education programme has to renovate in all the five degrees, namely; intermediate, college, bachelor's, master's and doctorate degrees, with a view to providing a comprehensive foundation for professional careers in libraries and centers of information, archives offices and others engaged in information activities, meeting the requirements of international integration and catching up to the level of with advanced countries' level.

\subsubsection{Forming Interdisciplinary Research Teams}

- Organize, manage and storing scientific and technological documents in libraries and archival centers.

- Manage and secure electronic information in libraries and archival centers.

- Marketing documents in libraries and archival centers, etc.

In addition, the team may choose to approach a research subject in libraries or archives centers in many ways, based on the data of both library science and archival science. The team can also apply the theories of library science to studies on archival science or vice versa, which means applying archival science's theories to studies on library science.

On organizing and conducting researches, the views, knowledge and study methods of experts on science and archival science will be utilized. Researchers must understand and, respect, and work with each other on studying the same subject; they much discuss, compare, contrast, and combine the qualitative research method and the quantitative one, as well as practicality and interpretation, to resolve issues raised in the most comprehensive, objective and effective way. Thus, the perceptions of library science and archival science will be swirled together to create changes in the "quality" of scientific research. Heads of the research teams should select people with the ability to organize, to lead the group, to work in an appropriate direction, in order for an interdisciplinary academic environment to be formed; the head should also be able to deploy the interdisciplinary scientific programs of large, high valued scope, to listen to different opinions, to generalize, summarize and finalize the essence of the matters and phenomena studied. Due to the interdisciplinary study problems bearing significant differences, the formation of interdisciplinary research teams focuses on the ability to use simultaneously, wholly, and effectively many specialized methods for one same subject of study.

Government investment is requested for these teams to carry out topics of large scale research leading to products for application in central libraries, information and archival offices.

\section{Conclusions}

Interdisciplinary approach in scientific research serves as a necessary and effective tool, bringing many advantages to the scientific community thanks to applying the viewpoints, knowledge and research methods of a number of scientists from various fields to solve the common problems in a most comprehensive, objective and effective way. It is a necessity to promote scientific research and the education of human resources of libraries and archives towards an interdisciplinary approach with a view to enhancing the strength of the scientific community and realizing the change in scientific research and training the human 
resources of these two professions in Vietnam.

\section{REFERENCES}

[1] Bui, L. T. (1997). The Current State and Future Development of Library Science in Vietnam - Hanoi. Vietnam Culture and Information Publishing House.

[2] Nguyen Thi Thuy B, \& Nguyen Thuy T, [2002], Scientific research work of the Department of Archives and State Archives in the period time 1962-2012, Journal Archives Vietnam, no. 8/2012-pp. 25-31.

[3] The master plan of development of record management, archives by 2020 and vision to 2030

[4] Kazancigil, A., \& Makinson, D. (2001). Les sciences sociales dans le monde. Les Editions de la MSH.

[5] Martínez-arellano. (2013). What is Library and Information Science (LIS) in Latin American Library schools. Retrieved fromhttp://revue.enssib.fr/what-library-and-information-scie nce-lis-latin-american-library-schools-mart\%C3\%ADnez-are llano-filiberto.
[6] Morin, E., Morin, E., Morin, E., \& Morin, E. (1990). Introduction à la pensée complexe (Vol. 96). Paris: Esf.

[7] Law on Archives, No.01 / 2011 / QH13 passed by the National Assembly of the Socialist Republic of Vietnam XIII course, the 2nd session adopted on 11/11/2011, the President signed Ordinance No. 10/2011 / L - CTN public issued on 25/11/2011, with effect from 01/07/2012 ;

[8] Decision No. 579 / QD - BNV dated 27/06/2012 of the Ministry of the Interior approved the Master Plan Documents, Archive 2020 , Vision 2030.

[9] Decree No. $01 / 2013$ / ND - CP of the Government dated 01.03.2013 " Regulations detailing the implementation of some articles of the Law on Archives"

[10] Decision No. 10/2007 / QD - BVHTT 04/5/2007 approving the development plan of the Library of Vietnam till 2010 and orientations to 2020 .

[11] http://ussh.vnu.edu.vn/de-nghien-cuu-lien-nganh-that-su-taora-nhung-thay-doi-ve-chat/194

[12] http://www.vanhoahoc.vn/nghien-cuu/ly-luan-van-hoa-hoc/v hh-phuong-phap-nghien-cuu/2082-van-de-lien-nganh-trongvan-hoa-hoc-1-van-hoa-doi-tuong-van-hoa-va-phuong-phapnghien-cuu-lien-nganh.html 